\title{
LYNTERIS C. (ED.) (2019), FRAMING ANIMALS AS EPIDEMIC VILLAINS. HISTORIES OF NON- HUMANS DISEASE VECTORS, LONDRES, PALGRAVE MACMILLAN, 245 PP.
}

\author{
Nicolás Facundo Rojas*
}

La serie de análisis de caso editados por el antropólogo de la Universidad de Saint Andrews Christos Lynteris en este libro, en el cual se abordan las historias de diversos hospedadores y transmisores de enfermedades no humanos y, a través de estas, de la emergencia de marcos conceptuales epidemiológicos y sanitarios en los cuales se insertaron, cobró una inusitada actualidad en el contexto de la salud global de fines del ańo 2019. El nuevo año se abrió con la irrupción de una temible epidemia que tuvo su origen en un fenómeno de spillover, el "salto" de un virus o bacteria presente en el organismo de un animal -un "reservorio natural"- hacia un hospedador humano. Guiados por una preocupación análoga, en los siete trabajos contenidos en el libro, que dialogan con el enfoque One Health-cuyo supuesto principal es que arribar a una comprensión más acabada de la salud pública, y no tan solo sobre las enfermedades zoonóticas, requiere de un análisis sobre la interdependencia ecológica entre humanos y no humanos-, antropólogos e historiadores analizan el modo en que la interacción entre humanos y ratas, marmotas, perros y mosquitos llevó a esta serie de animales que pueblan los márgenes e intramuros de pueblos y ciudades a ser conceptualizados como fuentes de eventuales epidemias y, posteriormente, de fenómenos pandémicos. Cabe hacer una sucinta reconstrucción del contexto en el cual el libro, publicado a fines de octubre de 2019, se inscribió, dado que, a través de esta, se puede ejemplificar el tipo de propuesta analítica que los distintos autores plantean.

* Becario en el Instituto de Salud Colectiva de La Universidad Nacional de Lanús (Isco-UNLa). Maestrando en la Maestría en Epidemiología, Gestión y Políticas de Salud (IsCo-UNLa). Correo electrónico: <rojasnicolas82@gmail.com>. 
A fines de diciembre, durante el comienzo de la temporada estacional de gripe, y cuando las autoridades sanitarias municipales se encontraban en alerta, 27 infectados con una neumonía viral cuyo cuadro clínico la relacionaba con la Parainfluenza, el Adenovirus y el Coronavirus, pero cuyo patógeno era desconocido, ingresaron en el Hospital de Enfermedades Infecciosas de la ciudad de Wuhan, una enorme urbe en el centro de China, capital de la provincia de Hubei (wмHC, 2019a; 2019b). Las autoridades de la Comisión Municipal de Salud, si bien anunciaron que la epidemia podía ser prevenida -tan solo algunos días antes, en Qatar, fueron anunciados por la Organización Mundial de la Salud tres casos de una gripe con características similares, el MERS-coV (Morvan, 2019)-, encargaron una serie de investigaciones de laboratorio al Instituto de Virología de Wuhan, dirigido por el Dr. Peng Zhou, también integrante del Centro de Bioseguridad de la Academia de Ciencias de China. Un grupo liderado por Peng Zhou, junto con otros especialistas del Hospital Jinyitan de Wuhan y el Centro de Prevención y Control de Enfermedades de Hubei, determinó en cuestión de semanas que la identidad de la secuencia general del genoma del nCoV2019 -la identificación utilizada por la Organización Mundial de la Salud para nombrar a la misteriosa neumonía viral de Wuhan- era similar en casi un 93\% a un tipo de Coronavirus, el BatCoV RaTG13, que podía encontrarse en los murciélagos de la especie Rhinolophus affinis distribuidos en la provincia de Yunnan (Zhou et al., 2020). Casi en simultáneo, un grupo conformado por especialistas de todo el país y liderado por Wei Ji, microbiólogo de la Escuela de Ciencias Médicas de la Universidad de Pekín, llevó a cabo una investigación cuyos resultados fueron publicados en el Journal of Medical Virology. El grupo de Wei Ji, al comparar el codon del nCoV2019 con el de distintas especies animales -marmotas, gallos, serpientes y murciélagos-, halló una relación estrecha entre la secuenciación del codon seleccionado por el virus y los codones de dos especies de serpientes distribuidas en el sudeste asiático, Bungarus multicinctus y Naja atra (Wei Ji et al., 2020). Si bien la opinión de diversos especialistas y comunicadores científicos se decantó por los resultados del trabajo del grupo de Peng Zhou, que concluía que los murciélagos Rhinolophus affinis eran los reservorios primarios del virus, una ola de dimensiones globales reprodujo en artículos en portales de noticias, memes en redes sociales como Facebook e Instagram, documentales y noticieros televisivos una versión que se encontraba en consonancia con las sospechas iniciales de la Comisión Municipal de Salud de Wuhan: el virus fue transmitido a los humanos por alguna de las innumerables especies de animales silvestres comercializadas en uno de los principales -y enormes- mercados de la ciudad, el Huanan 
Wholesale Seafood Market. Aunque médicos, epidemiólogos y diversos especialistas no arribaron a un acuerdo acerca de los mecanismos específicos de transmisión del virus entre humanos y no-humanos, la versión de la existencia de un vínculo entre las tradiciones culinarias chinas -en particular el consumo crudo de animales "exóticos" silvestres-y la emergencia de un paciente cero en Wuhan se expandió y circuló con fuerza.

Siguiendo la conceptualización que los trabajos editados en este libro plantean, estos animales no-humanos silvestres fueron puestos en el lugar de "villanos epidémicos"-epidemic villains- a través de su posicionamiento como objetos de indagación biomédica, pero también de su inserción en redes de significado más amplias, alejadas del discurso académico-científico. Tal y como señala Frédéric Keck en el post scriptum del libro, la palabra "villain" cargó históricamente un contenido semántico negativo, haciendo referencia a los sujetos "peligrosos" que habitaban en las afueras de aldeas, pueblos y ciudades, tanto humanos como no-humanos. De este modo, en los casos analizados las trayectorias sociales de estos animales transcurrieron desde ser percibidos como "indeseables" -vermins- hasta desplazarse a la posición de enemigos de la salud pública-epidemic blame-, integrados a las políticas sanitarias nacionales como pasibles de ser exterminados. Asimismo, a través de una fuerte interrelación entre poder político y conocimiento tecnocientífico, estos animales no-humanos pasarían a conformar los marcos conceptuales de las ciencias biomédicas -tal es el caso, por ejemplo, de los modelos explicativos de la epidemiología- englobados bajo el concepto de "vectores". Este fenómeno de conceptualización y reconceptualización -que implica que estos no humanos, luego de ser identificados como reservorios y transmisores de enfermedades infecciosas, sean configurados como "villanos" de la salud pública y objeto de políticas sanitarias de erradicación y exterminio- es analizado a lo largo de la obra, pero especialmente en los trabajos de Christos Lynteris y Karen Sayer que abren el libro.

En el caso del primero, centrado en la trayectoria de las marmotas sibiricas en Manchuria y Mongolia, Lynteris muestra cómo estos animales fueron el centro de una controversia científica internacional, en la cual se debatió acerca de su papel como transmisores de una variante de la peste pandémica, la peste neumónica y, luego del estudio de la persistencia de la enfermedad en su organismo -aparentemente condicionada por sus largos períodos de hibernación- fueron conceptualizados como un reservorio natural de la enfermedad. En el caso del trabajo de Karen Sayer sobre las ratas en el contexto del arribo de la pandemia de peste bubónica a Suffolk, Inglaterra, la autora analiza cómo la presencia masiva de los roedores en las zonas portuarias, en particular la presencia de sus cadáveres -signo de la 
peste-, se tornó una preocupación para las autoridades de la isla. La principal acción gubernamental en los distintos condados consistió en iniciar una política de destrucción de estos animales, al tiempo que sus cadáveres, vísceras, y luego sus pulgas se tornaban un objeto de indagación científica inserto en un complejo andamiaje de artefactos -laboratorios, microscopios, cámaras fotográficas y dispositivos visuales- condicionados a su vez por las políticas de administración sanitaria en los territorios coloniales, principalmente en el Raj británico de la India, uno de los primeros puntos afectados por la pandemia. Incluso en fechas tardías, ya en la segunda mitad de la década del 1910 las autoridades seguirán apelando a las políticas de exterminio ante la aparición de cadáveres y la sospecha de nuevos brotes. Como señala la autora:

[...] la gestión rigurosa de los animales no-humanos en el paisaje, así como también los procesos de destrucción, estudio, administración y control ejercido a través de la observación de las alimañas (vermin), generaron conexiones, nuevas temáticas de estudio, conocimientos y, por lo tanto, poder sobre la "invasión" de ratas y Yersinia pestis" (Sayer, 2019: 50).

Si bien el libro cubre un amplio marco temporal que se inicia en algunos trabajos en el momento en que comenzaron a circular las primeras representaciones de causalidad de enfermedades luego conceptualizadas como zoonóticas -es el caso de la investigación de larga duración de Deborah Nadal sobre el control de la rabia en la India Colonial y postindependentista-, el énfasis está puesto en el período histórico que se abre con la "revolución bacteriológica", el auge de la medicina de laboratorio y la consolidación de los sistemas de salud nacionales, como es el caso de los estudios de Lynteris y Sayer, y también el de Maurits Bastiaan Meerwijk sobre la construcción del "mosquito tigre" como un "asesino" despiadado para la salud global. Asimismo, la serie de trabajos autoría de los brasileños Gabriel Lopes, Gustavo Correa Matta, Carolina de Oliveira Nogueira, Elaine Teixeira Rabello y Lenir da Nascimiento Da Silva, quienes analizan el caso de la trayectoria del mosquito Aedes aegypti en Brasil -el cual, luego de la emergencia del dengue y el Zika como amenazas a la salud pública, volvió a estar en el centro de las políticas de control y erradicación-, se centran en un período que se inicia luego de la década de 1970 hasta la actualidad. También es el caso del trabajo de Séverine Thys sobre una enfermedad emergente, el Ébola, que la lleva a analizar el papel de las explicaciones populares y biomédicas en el contexto de la emergencia de la epidemia en Macenta, Nueva Guinea, en los años 2014-2016. La división en estos dos 
períodos no es arbitraria, antes bien el corte indica, como señala Lynteris, el paso de un "régimen de prevención y esperanza" -que alcanzó su auge en torno a la década de 1920 y se encontraba centrado en el control y la prevención de las enfermedades infecciosas de origen bacteriano- a un nuevo "régimen de emergencia" -en el cual los preparativos para enfrentar eventuales pandemias catastróficas a escala global y la preocupación por los fenómenos de spillover son la norma.

¿Cuál es la relevancia teórico-conceptual y empírica del libro para el contexto argentino, en particular para los estudios sociales de la ciencia, la tecnología y la salud locales? El principal objetivo de los autores de los trabajos editados en este libro es avanzar hacia una historia de los vectores nohumanos de enfermedades, y, en particular, a los que despiertan preocupación por su rol en eventuales fenómenos epidémicos, una problemática que en la Argentina está siempre presente: basta ver los recientes brotes de Hantavirus en Neuquén y de dengue en la región del litoral, una cuestión escasamente abordada por las ciencias sociales locales en sus dimensiones institucionales y políticas, así como también en cuanto a la producción y el uso de conocimientos tecnocientíficos. Además, en el contexto de la emergencia de la epidemia de nCoV2019, el debate sobre la interacción entre especies y su relación con la salud pública -no solo para los lectores académicos del mundo angloparlante, sino también para lectores latinoamericanos, ya sean científicos sociales, epidemiólogos, médicos o tomadores de decisión- adquiere cierta relevancia.

En cuanto a su relevancia teórico-conceptual, los autores, al centrarse en los animales no-humanos, analizan las distintas dimensiones que estuvieron involucradas en su configuración como "epidemic villains" -políticas, pero sobre todo intelectuales, científicas y visuales-, así como el marco institucional en el cual operaron las políticas de erradicación y exterminio ejercidas sobre aquellos. Esta conceptualización, que dialoga con las propuestas de autores inscriptos en el giro ontológico y el multinaturalismo -principalmente los trabajos del antropólogo francés Philippe Descola-, puede resultar fructífera para llevar a cabo análisis sobre uno de los principales intereses de los estudios sociales de la ciencia y la tecnología: la emergencia, conformación y consolidación de alianzas heterogéneas.

\section{REFERENCIAS BIBLIOGRÁFICAS}

Ji, W. et al., (2020), "Homologous recombination within the spike glycoprotein of the newly identified coronavirus 2019-nCoV may boostcross-spe- 
cies transmission from snake to human", Journal of Medical Virology, vol. 92, No 4, pp. 433-440.

Morvan, J. (2019), "Nouveaux cas de syndrome respiratoire du Moyen-Orient à Coronavirus (MERS-CoV) au Qatar", Médecine des voyages, 27 de diciembre. Disponible en: <https://www.medecinedesvoyages.net/medvoyages/ news/14930-nouveaux-cas-de-syndrome-respiratoire-du-moyen-orient-acoronavirus-mers-cov-au-qatar>.

Sayer, K. (2019), "Vermin Landscapes: Suffolk, England, Shaped by Plague, Rat and Flea (1906-1920)", en Lynteris, C. (ed.), Framing Animals as Epidemic Villains. Histories of Non-Humans Disease Vectors, Londres, Palgrave MacMillan, pp. 27-64.

Wuhan Municipal Health Comission (whmc) (2019a), "The Wuhan Health and Health Commission on the current outbreak of pneumonia in our city". Disponible en: <http://wjw.wuhan.gov.cn/front/web/ showDetail/2019123108989>.

(2019b), "Flu season hasn't started yet. The Health Care System Ready for Flu Prevention and Control". Disponible en: <http://wjw.wuhan.gov. $\mathrm{cn} /$ front/web/showDetail/2019111108754>.

Zhou, P. et al. (2020), "Discovery of a novel coronavirus associated with the recent pneumonia outbreak in humans and its potential bat origin", BioRxiv. Disponible en: <https://www.biorxiv.org/content/10.1101/2020 .01.22.914952v1>.

Artículo recibido el 14 de febrero de 2020. Aprobado para su publicación el 26 de mayo de 2020. 